Original Article

\title{
EVALUATION OF ANTI-INFLAMMATORY (IN VIVO) ACTIVITY OF ARIFLEX LINIMENT IN COMPARISON WITH DICLOFENAC GEL IN CARRAGEENAN INDUCED RAT PAW EDEMA MODEL
}

\author{
SANJAY NIPANIKAR ${ }^{*}$, S. S. CHITLANGE ${ }^{2}$
}

${ }^{1}$ Ari Healthcare Pvt. Ltd. Office No. 107, 1st Floor, S. No. 1, World Trade Center, Tower one, Opp. EON SEZ, Kharadi, Pune 411014, Maharashtra, India, ${ }^{2}$ Padmashree Dr. D. Y. Patil Institute of Pharmaceutical Sciences and Research, Pimpri, Pune 411018, Maharashtra, India

*Email: sanjay.n@arihealthcare.in

Received: 03 May 2021, Revised and Accepted: 25 Jun 2021

\begin{abstract}
Objective: The present study was conducted to evaluate anti-inflammatory activity of Ariflex liniment (conceptualized and developed by Ari Healthcare Pvt. Ltd) in comparison with Diclofenac gel in carrageenan induced rat paw edema model.

Methods: Wistar rats of either sex weighing 150-180 g were taken and divided into 3 groups with 6 animals in each group i.e. Group 1 (Controlled Group), Group 2 (Diclofenac gel) and Group 3 (Ariflex liniment). The study drugs were topically applied 30 min prior to carrageenan injection. After $30 \mathrm{~min} 1 \% \mathrm{w} / \mathrm{v}$ of $0.05 \mathrm{ml}$ carrageenan was injected subcutaneously in the paw. The paw was marked with ink at the level of lateral malleolus and immersed in mercury up to the lateral malleolus mark. The paw volume was measured plethysmographically, immediately after injection i.e. on 0
\end{abstract} min, and then on $30 \mathrm{~min}, 1 \mathrm{~h}, 2 \mathrm{~h}, 3 \mathrm{~h}, 4 \mathrm{~h}$ and $5 \mathrm{hr}$ after injection.

Results: Diclofenac gel sodium treated group showed significant inhibition ( $\mathrm{p}<0.01)$ of paw edema at $30 \mathrm{~min}, 1,2,3,4$ and 5 th hrs as compared to control group. Ariflex Liniment showed significant inhibition ( $<<0.05)$ of paw edema at $30 \mathrm{~min}, 1,2,3$, and 4 th hrs as compared to the control group. Group treated with Ariflex Liniment did not show any significant decrease in paw edema volume at 5 th hrs when compared to the control group.

Conclusion: Ariflex Liniment possesses anti-inflammatory activity.

Keywords: Ariflex liniment, Diclofenac gel, Anti-inflammatory activity, Carrageenan induced rat paw edema model

(C) 2021 The Authors. Published by Innovare Academic Sciences Pvt Ltd. This is an open access article under the CC BY license (https://creativecommons.org/licenses/by/4.0/) DOI: https://dx.doi.org/10.22159/ijcpr.2021v13i4.42747 Journal homepage: https://innovareacademics.in/journals/index.php/ijcpr

\section{INTRODUCTION}

Rheumatoid arthritis is one of the common autoimmune diseases. It is a chronic progressive inflammatory disorder affecting the synovial joints and typically producing symmetrical arthritis. If the inflammation goes unchecked it can damage bones and cartilage of the joint leading to deformity and disability. Several treatments are available for RA including prolonged use of NSAIDs (Non-steroidal anti-inflammatory Drugs), DMARDs (Disease-Modifying anti-rheumatic drugs), TNF inhibitors (tumor Necrosis factor inhibitors) and joint surgeries in severe cases. Though these medications are better treatment options for RA management, the side effects of these medications such as osteoporosis, gastric ulcers, nephrotoxicity etc. make them unsuitable for long-term use. And people tend to search for alternative medicinal drugs for the management of pain and inflammation of joints [1].

$\mathrm{OA}$ is the most common form of arthritis and is estimated to be the eighth leading cause of disability in the world [2]. It is more common in women than men. In India, $\mathrm{OA}$ is the most frequent joint disease with a prevalence of $17 \%$ to $60.6 \%$ (Sharma MK et al. 2007) [3]. Also, it is second most common rheumatological problem in India [4].

Osteoarthritis $(\mathrm{OA})$ is a chronic degenerative joint disease characterized by loss of or injury to articular cartilage, sub-chondral thickening, hypertrophy of bone and alterations of the synovial membrane and joint capsule [4]. In OA, bone rubbing causes pain, swelling and restricted range of motion at the affected joint. The joint may also lose its normal shape. In the normal adult, articular cartilage consists of a delicate system of cells and matrix proteins, which have the function of creating a viscoelastic tissue with high biomechanical stability and low friction. Articular cartilage remains stable, if the process of degeneration and regeneration of cells and matrix proteins occurs in equilibrium. Chondrocytes are the cartilage cells, which produce and maintain the cartilaginous matrix, which consists mainly of collagen and proteoglycans. The alteration of chondrocyte transplantation and degeneration of cartilage due to various triggering factors causes $\mathrm{OA}$ [5].
Presently very few underlying factors are known to cause OA. But, some common factors such as age, sex, obesity, genetics, bone density, smoking, local factors including trauma are main contributors in the pathogenesis of OA. OA with no known cause is termed as primary $\mathrm{OA}$ and it is mostly related to aging. Secondary $\mathrm{OA}$ results as a result of another disease or condition. The abovementioned factors initiate alterations in the equilibrium of cartilage formation and enhance degenerative cascade thus cause OA $[4,5]$.

Generally, OA is managed by symptomatic treatment methods such as use of pain and inflammation medications. NSAIDs (Diclofenac, Aceclofenac), and acetaminophen are considered to be the first-line therapy in the management of OA. Selective COX II inhibitors are widely recommended by virtue of their efficacy and relatively lower adverse effects. Also, the symptomatic slow-acting drugs for OA (SYSADOA) such as diacerein, hyaluronic acid (HA), chondroitin sulfate are useful in OA management [6]. In OA; intra-articular corticosteroid injections are believed to be most effective in patients with evidence of inflammation, effusion, or both. Various other therapies such as transcutaneous nerve stimulation, thermal modalities, acupuncture, and surgery (including joint replacement) have also been used to treat OA. Currently, though pharmacological, mechanical and surgical interventions are used, there is no known cure for OA. Also, above mentioned treatment options lead to many side effects and drawbacks. Thus, physicians and patients tend to move towards the use of alternative treatment methods [6-8].

In the view of this situation, Ari Healthcare Pvt. Ltd. has conceptualized and developed Ariflex Liniment. It is a polyherbal formulation used topically for the effective management of Arthritis. Maha Vishagarbha Taila (Ayurvedic Classical Formulation) [9], Gandhapura Taila (Gaultheria fragrantissima) [10], Tailaparnah Taila (Eucalyptus globulus) [11], Katuveera Arka (Capsicum annuum) [12], Menthol (Mentha arvensis) [13], Karpoora (Borneo camphor) [14] and Linseed Oil (Linum usitatissimum) [15] are used in Ariflex Liniment. It is recommended for use in Joint pain and inflammation, Muscle strain and Muscle sprain. 
The present study was conducted to evaluate anti-inflammatory (in vivo) potential of Ariflex Liniment in comparison with Diclofenac gel in carrageenan induced rat paw edema.

\section{MATERIALS AND METHODS}

\section{Study site}

The study was conducted at Padmashree Dr. D. Y. Patil Institute of Pharmaceutical Sciences and Research, Pimpri, Pune-411018. The material used for the study is given in table 1.

\section{Ethical consideration and approval}

Institutional Animal Ethics Committee (IAEC) has approved the study in the meeting held on 31 st Dec 2014. The protocol no. approved was DYPIPSR/IAEC/14-15/P-03.

\begin{abstract}
Anti-inflammatory activity of Ariflex liniment against carrageenan induced paw edema in rats
\end{abstract}

Wistar rats of either sex weighing 150-180 g were taken and divided into 3 groups with 6 animals in each group. Group 1(Controlled Group) animals were starved overnight. Group 2 animals were topically applied with Diclofenac gel as Standard drug and Group 3 Animals were topically applied with Ariflex liniment as test drug. The test and standard drugs were topically applied 30 min prior to carrageenan injection. After $30 \mathrm{~min} 1 \% \mathrm{w} / \mathrm{v}$ of $0.05 \mathrm{ml}$ carrageenan was injected subcutaneously in the paw. The paw was marked with ink at the level of lateral malleolus and immersed in mercury up to lateral malleolus mark. The paw volume was measured plethysmographically, immediately after injection i.e. on $0 \mathrm{~min}$, and then on $30 \mathrm{~min}, 1 \mathrm{~h}, 2 \mathrm{~h}, 3 \mathrm{~h}, 4 \mathrm{~h}$ and $5 \mathrm{hr}$ after injection.

Table 1: Materials used for the study

\begin{tabular}{ll}
\hline Material & Make \\
\hline Carrageenan & Irish moss \\
Diclofenac Gel & Novartis \\
Ariflex liniment (AHPL/AYTOP/0314) & Ari Healthcare Pvt. Ltd., Pune \\
\hline
\end{tabular}

Table 2: Animals used for the study

\begin{tabular}{|c|c|c|c|c|c|}
\hline S. No. & Species & Age in weeks & Weight/Size in gm & Gender & Numbers to be used \\
\hline 1 & Wister Rat & $6-8$ & $150-180$ & Male & 40 \\
\hline
\end{tabular}

\section{RESULTS}

The development of the edema in the rats after injection of Carrageenan has been described as biphasic event. In the first phase histamine, serotonin and kinins are released and in second phase mostly prostaglandins are released. Diclofenac gel sodium (Standard) treated group showed significant inhibition $(\mathrm{p}<0.01)$ of paw edema at $30 \mathrm{~min}, 1$, $2,3,4$ and $5^{\text {th }} \mathrm{h}$ as compared to control group. Groups treated with Ariflex Liniment showed significant inhibition $(\mathrm{p}<0.05)$ of paw edema at $30 \mathrm{~min}, 1,2,3$, and 4 th $\mathrm{hr}$ as compared to control group. Groups treated with Ariflex Liniment did not show any significant decrease in paw edema volume at $5^{\text {th }} \mathrm{h}$ when compared to control group.

Table 3: Anti-inflammatory activity of Ariflex Liniment using carragenan induced rat paw edema model

\begin{tabular}{|c|c|c|c|c|c|c|c|}
\hline \multirow{2}{*}{ Group } & \multicolumn{7}{|c|}{ Paw edema volume (ml) (mean \pm SEM) } \\
\hline & $0 \mathrm{~min}$ & $30 \mathrm{~min}$ & $\mathbf{1 h}$ & $2 \mathrm{~h}$ & $3 \mathbf{h}$ & $4 h$ & $5 \mathbf{h h}$ \\
\hline Control & $3.08 \pm 0.19$ & $1.62 \pm 0.05$ & $2.22 \pm 0.24$ & $2.92 \pm 0.26$ & $3.32 \pm 0.25$ & $2.48 \pm 0.25$ & $2.28 \pm 0.2$ \\
\hline STD (Diclofenac Gel) & $2.35 \pm 0.05$ & $0.578 \pm 0.11^{* *}$ & $0.87 \pm 0.26^{* *}$ & $1.108 \pm 0.14^{* *}$ & $1.064 \pm 0.29^{* *}$ & $0.6 \pm 0.29^{* *}$ & $1.11 \pm 0.39^{* *}$ \\
\hline Ariflex Liniment & $2.56 \pm 0.12$ & $1.22 \pm 0.23^{*}$ & $1.46 \pm 0.07^{*}$ & $1.36 \pm 0.07^{*}$ & $2.54 \pm 0.08^{*}$ & $1.56 \pm 0.06^{*}$ & $1.6 \pm 0.11^{\mathrm{ns}}$ \\
\hline
\end{tabular}

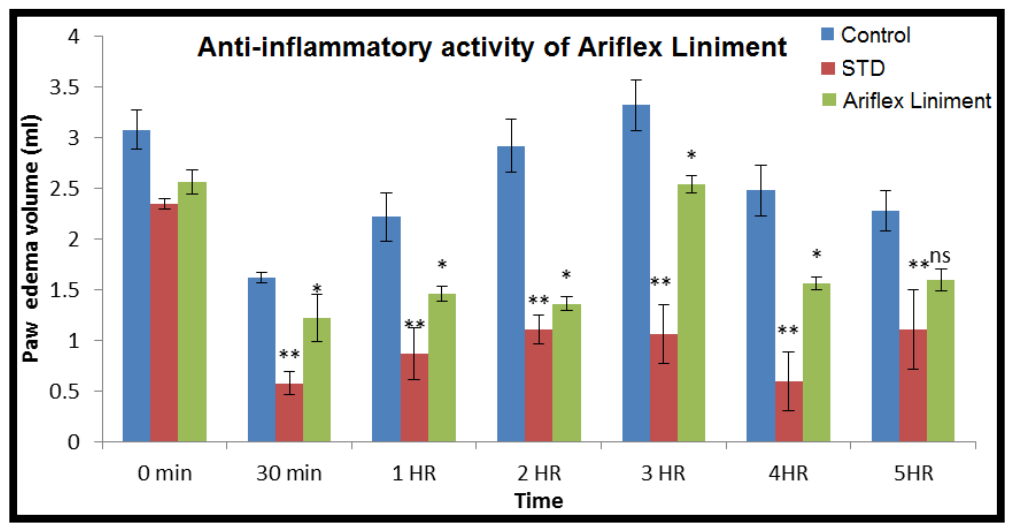

Fig. 1: Anti-inflammatory activity of Ariflex Liniment with standard and control, Data is expressed as mean \pm SEM of $n=5$ observations. All treatments were compared with control (ANOVA followed by Dunnett's test) ${ }^{* *} \mathbf{p}<0.01,{ }^{*} \mathbf{p}<0.05$

\section{DISCUSSION}

Osteoarthritis (OA) is a chronic degenerative joint disease characterized by loss of or injury to articular cartilage, sub-chondral thickening, hypertrophy of bone and alterations of the synovial membrane and joint capsule.
Various NSAIDS, analgesics, paracetamol, COX-2 inhibitors that reduce pain and inflammation in $\mathrm{OA}$ and other drugs like Chondroitin sulfate, diacerein, hyaluronic acid are generally used for the treatment of OA. Intra-articular steroid injection provides excellent symptomatic relief but fails to provide permanent relief. Various other therapies such as transcutaneous nerve stimulation, 
thermal modalities, acupuncture, and surgery (including joint replacement) have also been used to treat OA. Though pharmacological, mechanical and surgical interventions are used, there is no known cure for OA. Also, above mentioned treatment options lead to many side effects and drawbacks like nephrotoxicity with Diclofenac and hepatotoxicity with paracetamol, osteoporosis with corticosteroids on their long term irrational use. Hence patients tend to search safer and effective alternative therapeutic options [1].

Keeping in mind the need of the time to have drugs with minimum side effects, Ari Healthcare Pvt. Ltd. has conceptualized and developed Ariflex Liniment for the treatment of Arthritis.

In the present study evaluation of anti-inflammatory activity (in vivo) of Ariflex liniment in comparison with Diclofenac Gel in carrageenan induced rat paw edema model was done. It was observed from the results of the present study that Ariflex liniment possesses antiinflammatory activity in rat paw edema model. The action of Ariflex liniment started immediately. At the end of $30 \mathrm{~min}$ inflammation was reduced by almost $53 \%$ compared to $75 \%$ of diclofenac gel. Antiinflammatory effect of the Ariflex liniment sustained till the end of $5 \mathrm{~h}$. The anti-inflammatory activity of Ariflex liniment was found to be close to that of Diclofenac gel used as standard.

Ariflex Liniment contains Maha Vishagarbha Taila (Ayurvedic Classical Formulation) [9], Gandhapura Taila (Gaultheria fragrantissima) [10], Tailaparnah Taila (Eucalyptus globulus) [11], Katuveera Arka (Capsicum annuum) [12], Menthol (Mentha arvensis) [13], Karpoora (Borneo camphor) [14] and Linseed Oil as base (Linum usitatissimum) [15].

Maha Vishagarbha Taila is medicated oil composed of more than 50 different herbs. In Ayurveda, its use is recommended in various Vatavyadhis (musculoskeletal disorders). Its topical application over affected area is said to relieve the stiffness (Sarvangagraha) [9].

Gandhapura Taila (Gaultheria fragrantissima) is widely used topically in the management of various types of arthritis [16]. Methyl salicylate and its glycoside derivatives obtained from this species are reported to possess remarkable anti-inflammatory and analgesic properties [10]. Gandhapura Taila is standardized to $95 \%$ methyl salicylate.

Tailaparnah Taila (Eucalyptus globulus) is a volatile oil obtained from Eucalyptus globulus, traditionally used in the treatment of upper respiratory tract infections, wounds, fever and rheumatism. Anti-inflammatory and analgesic activities of Eucalyptus oil are reported in various studies [11].

Katuveera Arka is obtained from Capsicum annuum. The active ingredient, Capsaicin is supposed to be responsible for its pharmacological activities. Capsaicin binds to specific receptors/nociceptors in the skin, which initially causes a state of neuronal excitation and a period of increased local sensitivity. This results in burning sensation, stinging, and itching associated with cutaneous vasodilation. These manifestations are attributed to the stimulation of afferent C-fibers and the release of substance P. Soon after, a refractory period occurs with reduced sensitivity. Depletion of substance $\mathrm{P}$ and degeneration of peripheral nerve fibres occurs on repeated application and reduced sensitivity persists. Its effectiveness in treating pain associated with Osteoarthritis and Rheumatoid arthritis is documented [17].

Menthol is obtained from the oil of plant Mentha arvensis. Methanolic extracts of this plant are reported to possess significant antiinflammatory and anti-arthritic activities in experimental studies [18].

Menthol is a topical vasodilator that enhances the absorption of other topical skin medications. It is said to stimulate the cold receptors on the skin and dilate the blood vessels causing cooling and analgesic effects. Menthol in low concentration causes cooling sensation and the same when applied topically in high concentration causes local anesthesia and pain relief. It is also reported to reduce histamine induced irritation and itching in some studies [19].

Karpoora is obtained from the plant Borneo camphora. Camphor is a known agonist of TRPV2, TRPA1 and TRPV1 quickly deactivating TRP channels. This results in long-term pain relief. It is a relatively weak sensory irritant having a modest excitatory effect on thermosensitive (and perhaps nociceptive) cutaneous fibers [14].

Studies have reported that combination of menthol with camphor enhances skin penetration of Methyl salicylate and inhibits both in vivo and in vitro synthesis of Methyl salicylate to salicylic acid [14].

Linseed oil is obtained from dried ripe seeds of Linum usitatissimum. It is a rich source oflomolenic acid which is proved to possess noticeable anti-inflammatory activity. Anti-inflammatory, analgesic and anti-oxidant properties of this edible oil are confirmed in various studies. Its topical use has been approved in various dermatological conditions [15].

It is evident form the above discussion that almost all ingredients of Ariflex liniment possess anti-inflammatory activity hence it can be concluded that anti-inflammatory effect of Ariflex liniment could be the synergistic action of these herbs.

\section{CONCLUSION}

It can be concluded that Ariflex liniment possess significant antiinflammatory effect which is close to that of Diclofenac gel. Thus Ariflex liniment can be used as an effective topical anti-inflammatory agent in various types of arthritis, joint pain and inflammation, muscle strain and muscle sprain.

\section{FUNDING}

Nil

\section{AUTHORS CONTRIBUTIONS}

All the authors have contributed equally.

\section{CONFLICT OF INTERESTS}

\section{Declared none}

\section{REFERENCES}

1. Hochberg MC, Altman RD, April KT, Benkhalti M, Guyatt G, McGowan J, et al. American college of rheumatology 2012 recommendations for the use of nonpharmacologic and pharmacologic therapies in osteoarthritis of the hand, hip, and knee. Arthritis Care Res 2012;64:465-74.

2. Nam JL, Wunthro KL, Vollenhoven RF Van, Pavelka K, Valesini G, Hensor EMA, et al. Current evidence for the management of rheumatoid arthritis with biological disease-modifying antirheumatic drugs: a systematic literature review informing the EULAR recommendations for the management of RA. Ann Rheum Dis 2010;69:976-86.

3. Radha MS, Gangadhar MR. Prevalence of knee osteoarthritis patients in Mysore city, Karnataka. Int J Recent Sci Res 2015;6:3316-20.

4. Mahajan A, Verma S, Tandon V. Osteoarthritis. JAPI 2005;53:634-41.

5. Tallheden T, Bengtsson C, Brantsing C, Carlsson L, Peterson L, Brittberg M, et al. Proliferation and differentiation potential of chondrocytes from osteoarthritic patients. Arthritis Res Ther 2005;7:R560-8.

6. Scheinfeld N. A comprehensive review and evaluation of the side effects of the tumor necrosis factor alpha blockers etanercept, infliximab and adalimumab. J Dermatol Treatment 2004;15:280-94.

7. Kongtharvonskul J, Anothaisintawee T, McEvoy M, Attia J, Woratanarat P, Thakkinstian A. Efficacy and safety of glucosamine, diacerein, and NSAIDs in osteoarthritis knee: a systematic review and network meta-analysis. Eur J Med Res 2015;20:24.

8. Tascioglu F, Armagan O, Tabak Y, Corapci I, Oner C. Low power laser treatment in patients with knee osteoarthritis. Swiss Med Wkly 2004;134:254-8.

9. Shastri B. Yogaratnakar with vidyotini commentary commentary. Shastri L, Poorvardha. Varanasi, Choukhamba Prakashan; 2012. p. 531.

10. Liu W, Qiao W, Liu Z, Wang X, Jiang R, Li S, et al. Gaultheria: phytochemical and pharmacological characteristics. Molecules 2013;18:12071-108. 
11. Silva I, Abebe W, Sousa S, Duarte V, Machado M, Matos F. Analgesic and anti-inflammatory effects of essential oils of eucalyptus. J Ethnopharmacol 2003;89:277-83.

12. Hernandez Ortega M, Ortiz Moreno A, Hernandez Navarro M, Chamorro Cevallos G, Dorantes Alvarez L, Necoechea Mondragon H. Antioxidant, antinociceptive, and antiinflammatory effects of carotenoids extracted from dried pepper (Capsicum Annuum L.). J Biomed Biotechnol 2012. DOI:10.1155/2012/524019

13. Rita de Cassia da Silveira e Sa. A review on anti-inflammatory activity of monoterpenes. Molecules 2013;18:1227-54.

14. Silva Filho SE, de Souza Silva Comar FM, LAM Wiirzler LAM, do Pinho RJ, Grespan R, Bersani Amado CA, et al. Effect of camphor on the behavior of leukocytes in vitro and in vivo in acute inflammatory response. Trop J Pharm Res 2014;13:2031-7.

15. Hashempur MH, Homayouni K, Ashraf A, Salehi A, Taghizadeh M, Heydari M. Effect of linum usitatissimum L. (linseed) oil on mild and moderate carpal tunnel syndrome: a randomized, doubleblind, placebo-controlled clinical trial. DARU 2014;22:43.

16. Chunekar KC. Bhavaprakasha nighantu of bhavamishra. Chaukhambha Publications; 2010. p. 809.

17. Flores MP, Castro A, Nascimento J. Topical analgesics. Rev Bras Anestesiol 2012;62:244-52.

18. Reddy V, Rao G, Lakshmi G. A review on anti-arthritic activity of some medicinal plants. J Global Trends Pharm Sci 2014;5:2061-73.

19. Balakrishnan A. Therapeutic uses of peppermint-a review. J Pharm Sci Res 2015;7:474-6. 